\title{
Prediction of decadal variability of sea surface temperature by a coupled global climate model FGOALS_gl developed in LASG/IAP
}

\author{
WU Bo* \& ZHOU TianJun \\ State Key Laboratory of Numerical Modeling for Atmospheric Sciences and Geophysical Fluid Dynamics (LASG), Institute of Atmospheric Physics, \\ Chinese Academy of Sciences, Beijing 100029, China
}

Received November 30, 2011; accepted February 23, 2012; published online April 24, 2012

\begin{abstract}
A decadal climate prediction was performed by a coupled global climate model FGOALS_gl developed by the State Key Laboratory of Numerical Modeling for Atmospheric Sciences and Geophysical Fluid Dynamics (LASG) within the Institute of Atmospheric Physics (IAP), Chinese Academy of Sciences. First, an Incremental Analysis Updates (IAU) scheme was applied to assimilate surface and subsurface ocean temperature and salinity fields derived from oceanic objective analysis data, for the initialization of the ocean component of the model. Starting from the initialized states, hindcast integrations were performed with the specified historical solar cycle variations, concentrations of greenhouse gasses and sulfate aerosol, following the standard 20C3M scenario used in phase three of the Coupled Model Intercomparison Project (CMIP3). Based on the hindcast integrations, we performed forecast integrations under the radiative forcing of the A1B scenario in the CMIP3. Compared with the 20C3M run, the hindcast integrations have a much higher ability to simulate the decadal variability of SST (Sea Surface Temperature) in the tropical central-eastern Pacific and mid-latitude northeastern Pacific. This suggests that the ocean initialization is able to enhance the model skill in the regions with large decadal variability. The forecast integrations suggest that the SST in the tropical central-eastern Pacific has reached its trough phase, and will gradually increase in the following 10-15 years. Meanwhile, the global mean surface temperature predicted by the forecast integrations increases slower than that projected by the A1B scenario run over 2000-2010, but faster than the latter after that.
\end{abstract}

decadal prediction, CGCM, IPCC AR5

Citation: Wu B, Zhou T J. Prediction of decadal variability of sea surface temperature by a coupled global climate model FGOALS_gl developed in LASG/IAP. Chin Sci Bull, 2012, 57: 2453-2459, doi: 10.1007/s11434-012-5134-y

Climate change over the next $10-30$ years, referred to as decadal climate variability, is an issue of great concern because of the potential substantial impacts on economic and social development $[1,2]$. The prediction of decadal variability is specified as one of the core experiments within phase five of the Coupled Model Intercomparison Project (CMIP5), the results of which will be used in the fifth assessment report (AR5) of the Intergovernmental Panel on Climate Change (IPCC) [3].

There are three main factors influencing the skill with which decadal variability is predicted namely, the external forcing, the inertia of the climate system, and the intrinsic variability of the climate system [1]. The external forcing

*Corresponding author (email: wubo@mail.iap.ac.cn) includes natural external forcing (solar cycle variation and volcanic eruption) and anthropogenic effects (emissions of greenhouse gasses and aerosol) [4]. The inertia of the climate system is caused by slow oceanic variability because of its large heat capacity and stable stratification. Previous studies found that even if the concentration of greenhouse gasses remained in the present state, the global mean surface temperature will increase at a rate of about $0.1^{\circ} \mathrm{C} / 10 \mathrm{a}$, to a total temperature increase of $0.6^{\circ} \mathrm{C}$ by 2100 [5]. The above two factors have been fully addressed in the studies of climate change during the last several decades. A series of numerical experiments reported on in the IPCC AR4 were conducted to project global temperature change over the next 100 years under different emission scenarios. However, the IPCC AR4 also noted that in terms of the results of 
the ensemble of coupled global climate models (CGCMs), the magnitude of the global temperature warming trend and its spatial pattern over the next several decades is not sensitive to the different emission scenarios [6].

Since 2007, some climate research centers tried to use CGCMs to make decadal climate predictions [7-10]. In contrast to climate prediction on interannual or shorter time scales, or climate projections on centurial or longer time scales, the decadal climate prediction is a combination of initial and external forcing factors, that is, both the model initial conditions and the external radiative forcing have impacts on the prediction results [1]. From a technical point of view, how to specify the external forcing is analogous to previous climate projection experiments, however, how to initialize CGCMs is still an open and challenging question. For example, Keenlyside et al. [7] applied a SST nudging approach, restoring the simulated SST to the observational SST. Based on the simple initialization approach, the CGCM ECHAM5/MPI-OM showed some skill in the prediction of decadal variation of the Atlantic meridional oscillation circulation (AMOC) and the climate in the North Atlantic Rim. Mochizuki et al. [8] used an Incremental Analysis Update scheme (IAU) to assimilate the ocean temperature and salinity over the upper $700 \mathrm{~m}$ derived from objective analysis data. They found that based on the initialization scheme, the CGCM MIROC showed some skill in the prediction of the Pacific decadal oscillation (PDO).

In this study, we used a state-of-the-art coupled global climate model FGOALS_gl developed in LASG/IAP/CAS to perform decadal climate prediction experiments. Based on the analysis of the experiment results, the experiment strategy was carried out by a new model version in LASG/ IAP to participate the CMIP5.

\section{Model, experiment design and data}

\subsection{The model}

FGOALS_gl is a low-resolution CGCM developed in the State Key Laboratory of Numerical Modeling for Atmospheric Sciences and Geophysical Fluid Dynamics (LASG) at the Institute of Atmospheric Physics (IAP), Chinese Academy of Sciences (hereafter LASG/IAP). It is designed for long-term and fast integrations [11]. Its atmospheric component is the low-resolution version of the Grid Atmospheric Model of IAP/LASG (GAMIL), with a horizontal resolution of $5^{\circ}$ (longitude) $\times 4^{\circ}$ (latitude) and 26 vertical levels [12]. The ocean component is the LASG/IAP Climate Ocean Model (LICOM), with a horizontal resolution of $1^{\circ} \times$ $1^{\circ}$ and 30 vertical levels [13]. The land and ocean ice components are the Community Land Model (CLM) [14] and Community Sea Ice Model (CSIM) [15], developed by the National Center for Atmospheric Research (NCAR). The four components are coupled through a coupler CPL5 developed by NCAR. The FGOALS_gl model has been used in the simulations of atmospheric temperature evolution in the 20th century [16]; tropical air-sea interaction [17]; cloudradiation feedback [18], climate change over the past millennium $[19,20]$ and North Pacific decadal variability [21].

\subsection{Experiment design}

The following three simulations were performed with the FGOALS_gl.

(1) The FGOALS_gl was integrated from 1850 to 2000, with the historical radiative forcing following the IPCC AR4 20C3M scenario. The radiative forcing fields include the concentrations of greenhouse gasses and sulfate aerosols, solar cycle variations and major volcanic eruptions. The radiative effects of the volcanic eruptions were considered by changing solar cycle variations. Subsequently the run was extended to 2020 under the A1B scenario. The total integration is referred to as $20 \mathrm{C} 3 \mathrm{M}+\mathrm{A} 1 \mathrm{~B}$ run.

(2) The Incremental Analysis Updates (IAU) scheme was used to assimilate ocean temperature and salinity over the upper $1000 \mathrm{~m}$ derived from the objective analysis data EN3_v2a. The assimilation integration was from 1950-2005. The assimilation processes were confined in $70^{\circ} \mathrm{S}-70^{\circ} \mathrm{N}$, in which $60^{\circ}-70^{\circ} \mathrm{S}$ and $60^{\circ}-70^{\circ} \mathrm{N}$ are set as transitional zones. Poleward of $70^{\circ} \mathrm{S}$ and $70^{\circ} \mathrm{N}$, the model components were freely coupled. The IAU scheme is an assimilation technology combining the aspects of the intermittent and continuous approaches, and has been used in the construction of atmospheric reanalysis systems [22]. Compared with the Nudging scheme, it can keep the analysis increment constant in a model's prognostic equation, and thus effectively filter out short-wave noises in the assimilation processes. It is worth noting that the experiments focused on the climate variability on the decadal time scale, but not the climatology. Therefore, we assimilated the anomalous fields relative to the 1960-1989 mean to minimize the impact of the assimilation processes on the model climatology. The initialization integration is referred to as INIT run.

(3) Eleven hindcast or forecast integrations were started every 5 years from 1955-2005, with the initial fields derived from the INIT run. All the hindcast and forecast runs integrated 10 years, except for that started from 2015, which integrated 15 years to 2020 . The radiative forcing used in the runs was same as that used in the $20 \mathrm{C} 3 \mathrm{M}+\mathrm{A} 1 \mathrm{~B}$ run. In addition, to minimize the possible impacts of the initial disturbance, all the runs were started from November of previous years, e.g. the 1970 run was started from November 1969. The outputs of the first 2 months were omitted. The runs started from the years before and after 1995 are referred to as Hindcast and Forecast runs, respectively.

\subsection{Data}

The following observation data were used in the study.

(1) Ocean temperature and salinity was derived from ob- 
jective analysis data EN3_v2a offered by the Met Office Hadley Centre, which is a production based on various observation data, including WOD05, GTSPP and Argo. The data underwent strict quantity control before being released. The data have a horizontal resolution of $1^{\circ} \times 1^{\circ}$, and have 42 levels in the vertical direction, with the deepest level reaching $4000 \mathrm{~m}$ [23].

(2) The global surface temperature anomaly data was HadCRUT3, offered by the Hadley Centre [24]. HadCRUT3 consists of combined data, whose land part is CRUTEM3 and ocean part is HadISST2. Its horizontal resolution is $5^{\circ} \times 5^{\circ}$.

(3) Sea surface temperature was HadISST2, offered by Hadley Center. The data have a horizontal resolution of $1^{\circ} \times 1^{\circ}[25]$.

All the data cover 1955-2005.

\section{Results}

As noted in the introduction, initial conditions play essential roles in decadal climate prediction. To evaluate the skill of the INIT run in initializing the ocean surface and subsurface states, we show the spatial distributions of the temporal correlation and root mean square error (RMSE) between the vertically averaged temperature over the upper $300 \mathrm{~m}$ simulated by the INIT run, and that derived from the objective analysis data. The correlation shows a zonal distribution, with values lower in the tropical $\left(10^{\circ} \mathrm{S}-10^{\circ} \mathrm{N}\right)$ and highlatitude (poleward of $60^{\circ} \mathrm{N}$ and $60^{\circ} \mathrm{S}$ ) oceans, while higher in the extra-tropical and mid-latitude oceans (Figure 1a).

The lower correlation in the high-latitude ocean is associated with the experiment design. The assimilation zone is
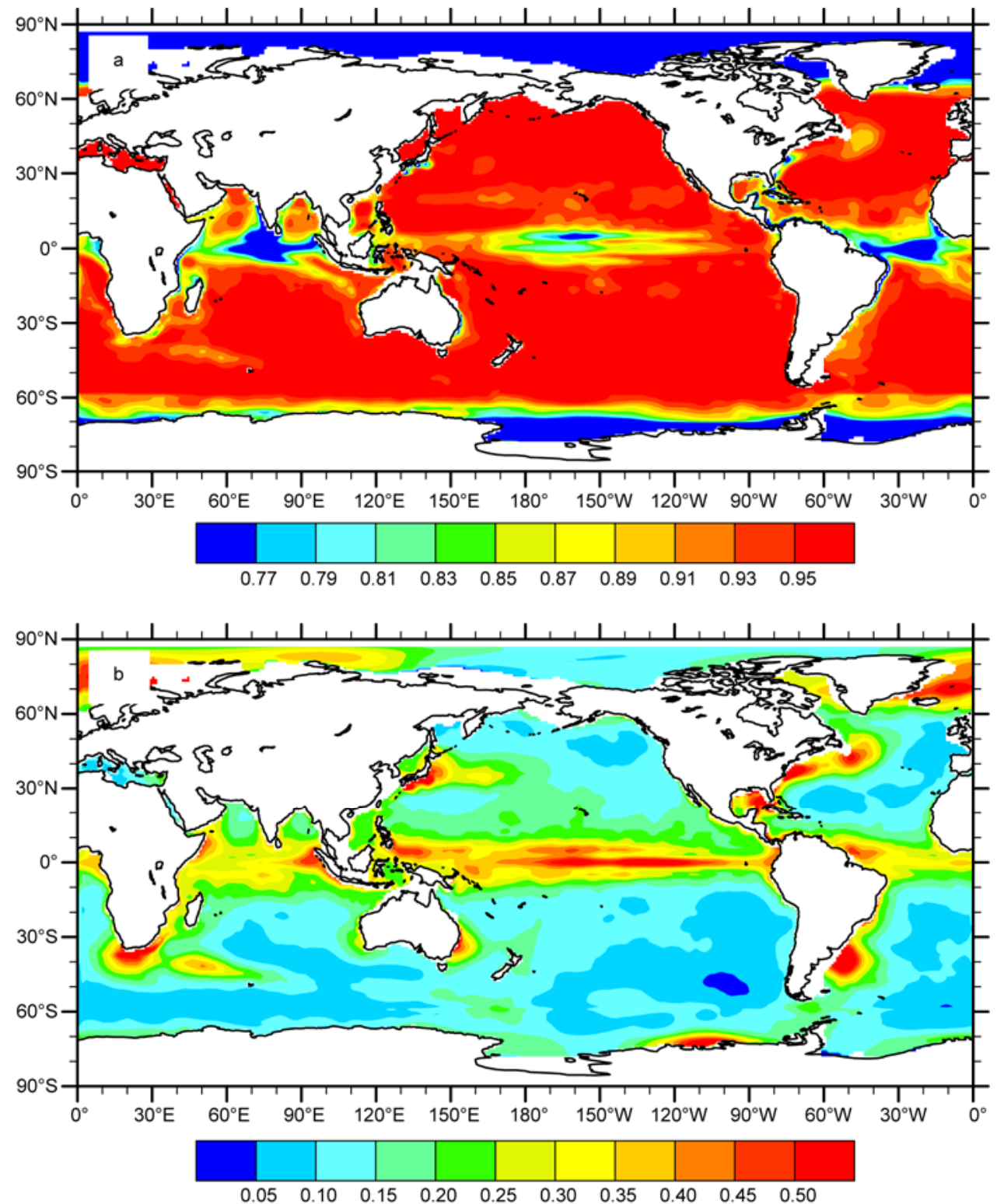

Figure 1 a, The spatial distribution of the temporal corelation between the vertically averaged ocean temperature over the upper $300 \mathrm{~m}$ simulated by the INIT run and that derived from the objective analysis data EN3_V2a; b, same as in a, but for the root mean square error (RMSE). 
confined in the $70^{\circ} \mathrm{N}-70^{\circ} \mathrm{S}$, thus the simulated ocean upper temperature in the high latitude is primarily modulated by the intrinsic variability of the model and does not correspond to the observations. However, the lower correlation in the tropical ocean is associated with different reasons. Compared with the mid-latitude ocean, the upper ocean heat capacity in the tropical ocean oscillates much more intensively and faster. The tropical ocean waves propagate much faster, and its amplitude is stronger, because of active air-sea interactions. In the assimilation processes, analysis increments can be seen as external forcing in the prognostic equation, which determines the prognostic variable together with the internal variability of the system. A larger internal variability will weaken the fractional contribution of the external forcing and thus make the assimilation skill worse. As a result, the correlation coefficients in the tropical ocean are about $0.7-0.8$, lower than that in the mid-latitude oceans (larger than 0.9).

Similar to the correlation, the RMSE also shows zonal distributions, that is, errors are larger in the tropical and highlatitude oceans, while smaller in the mid-latitude oceans. In addition, the errors in the regions of western boundary currents are significantly larger than that in the ocean interior (Figure 1b). The above analysis suggests that although the initialization has some biases and discrepancies, it does show high skill in the most areas, especially in the midlatitude ocean, which is the basis of our decadal climate prediction.

The spatial distribution of the correlation between the SST simulated by the Hindcast runs and the corresponding observation is shown in Figure 2a. The significant positive correlation is mainly located in the tropical Indian Ocean,
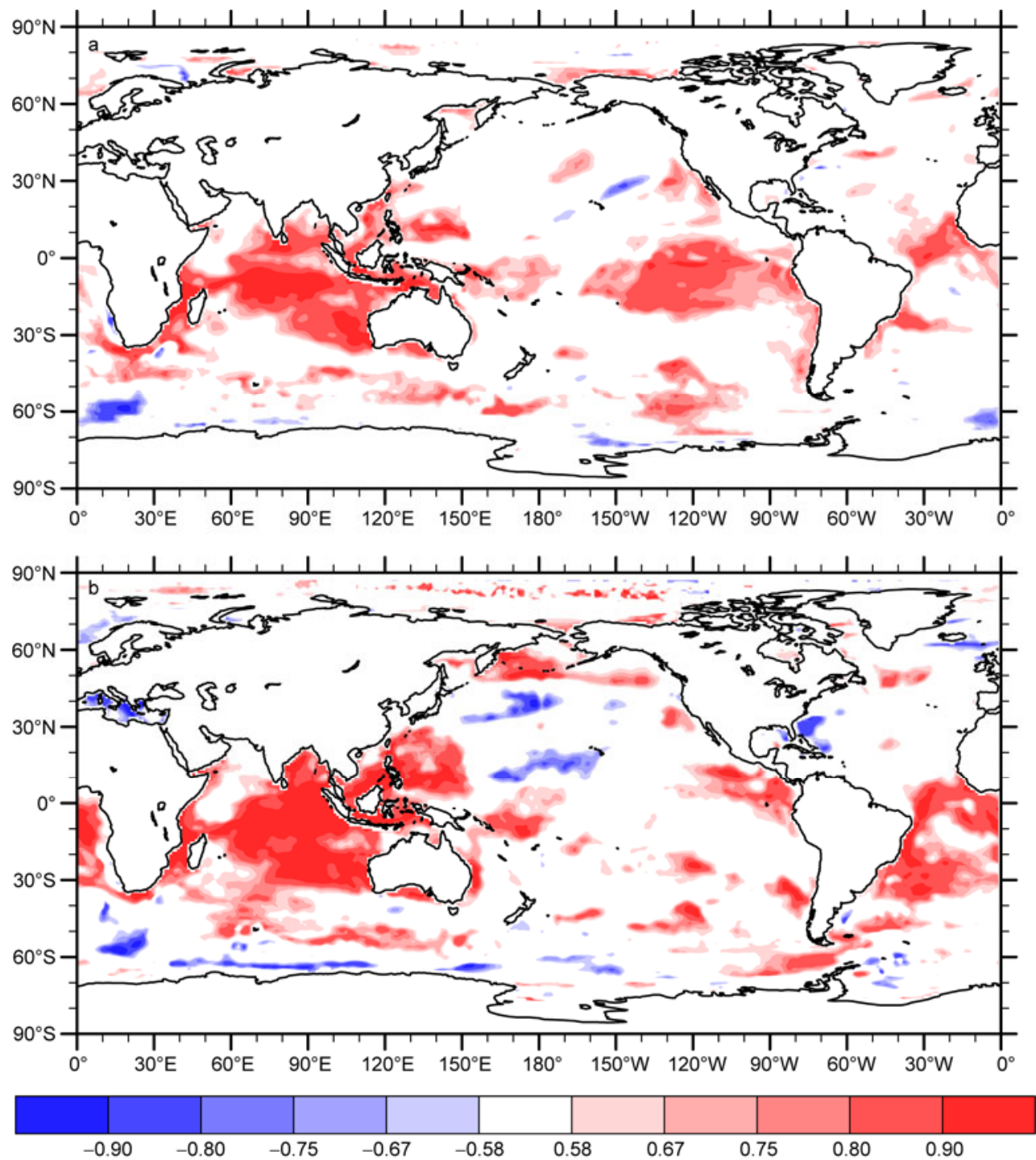

Figure 2 Correlation skills of the 10-year-mean SST predicted by the Hindcast runs and 20C3M run. Nine 10-year-long Hindcast runs are started every 5 years from 1955-1995. The 10-year-mean SST is calculated for each Hindcast run. Then the averaged SST of each corresponding period is calculated for the 20C3M run and the observation. a, The spatial distribution of the temporal correlation of the SST between the Hindcast runs and the observation; b, same as in a, but for the $20 \mathrm{C} 3 \mathrm{M}$ run. $0.58,0.67,0.75,0.8$ and 0.9 represent $10 \%, 5 \%, 1 \%, 0.1 \%$ and $0.01 \%$ significance levels of the Students' $t$-test, respectively. 
western North Pacific, central-eastern Pacific and Atlantic, indicating that the Hindcast runs have high skill in reproducing the tropical SST. In contrast, in the middle and high latitudes, the significant positive correlation is sporadic. It is worth noting that the significance of the correlation skill is influenced by the sample sizes. In the tropical central-eastern Pacific and mid-latitude northeastern Pacific, the auto-correlations are very small and the independent sample sizes are generally equal to the original sample sizes. However, in the tropical Indian Ocean, the situation is opposite. Large auto-correlations and the independent sample sizes that are much smaller than the original sample sizes, are consistent with previous study results that the SST in the zone have a strong warming trend, while there is a weak decadal variability [26].

The only difference between the Hindcast runs and 20C3M run is that the former are started from the initialized states, with the memory of the climate system. Thus, the 20C3M run is used as a benchmark to test the skill of the Hindcast runs. The Hindcast runs show higher skill in the tropical central-eastern Pacific and mid-latitude northeastern Pacific and lower skill in the tropical Indian Ocean than the 20C3M run (Figure 2a, b) The SST in the Indian Ocean primarily shows a warming trend as a response to anthropogenic forcing. The initialization may have a negative effect on the response and lower the model skill in the zone.

To clearly demonstrate the improvement of the Hindcast runs relative to the $20 \mathrm{C} 3 \mathrm{M}$ run, we shows the temporal evolutions of the area-averaged SST in the tropical centraleastern Pacific $\left(10^{\circ} \mathrm{S}-10^{\circ} \mathrm{N}, 90^{\circ}-150^{\circ} \mathrm{W}\right)$ and mid-latitude northeastern Pacific $\left(20^{\circ}-60^{\circ} \mathrm{N}, 105^{\circ}-140^{\circ} \mathrm{W}\right)$. In the observation, the SSTs in the two regions oscillate in the same phase, and both evolve from a negative phase to a positive phase in about 1980. The Hindcast runs realistically reproduce the SST evolutions in the two regions, with correlation coefficients reaching 0.82 and 0.75 for the tropical central-eastern Pacific and mid-latitude northeastern Pacific, respectively, much higher than 0.68 and 0.58 achieved in the $20 \mathrm{C} 3 \mathrm{M}$ run. In addition, the Hindcast runs capture the phase change of the decadal oscillations in 1980, while the 20C3M run fails to.

The most significant signal of the Pacific on the decadal time scale is the PDO, which is characterized by the seesaw structure of the SST in the Kuroshio-Oyashio Extension (KOE) and in the northeastern Pacific [27]. Although the Hindcast runs have high skill in the northeastern Pacific, it does not reproduce the SST variations in the KOE region (Figure 3c). Previous studies found that the decadal oscillation of the SST in the KOE region is associated with the oceanic Rossby wave-induced sea surface height anomalies stimulated by the Aleutian low anomalies [28]. Since the Aleutian low simulated by the FGOALS_gl is shifted northward relative to the observation, the simulated oceanic Rossby waves have large biases [11]. Thus, even though the initial condition is close to the observation, the SST decadal variation in the KOE region has large biases. It will be a challenging issue to improve the prediction skill of the PDO in the future decadal climate prediction experiments.

Based on the higher skills of the Hindcast runs in the tropical central-eastern Pacific and mid-latitude northeastern Pacific, we tried to predict the SST evolution in the two regions by the Forecast runs (Figure 3). It is worth noting that year in the following context represents a 10-year centered mean, e.g. 2000 represents the 10-year average of 1995-2004. The results indicate that the SST in the tropical central-eastern Pacific reached its trough phase in 2000. It will increase slowly some time, and then increase quickly after 2015. The SST in the central-eastern Pacific will reach its trough phase in 2005, and then gradually increase after that.

Besides the regional characteristics, the change of the global mean surface temperature over the coming decades is
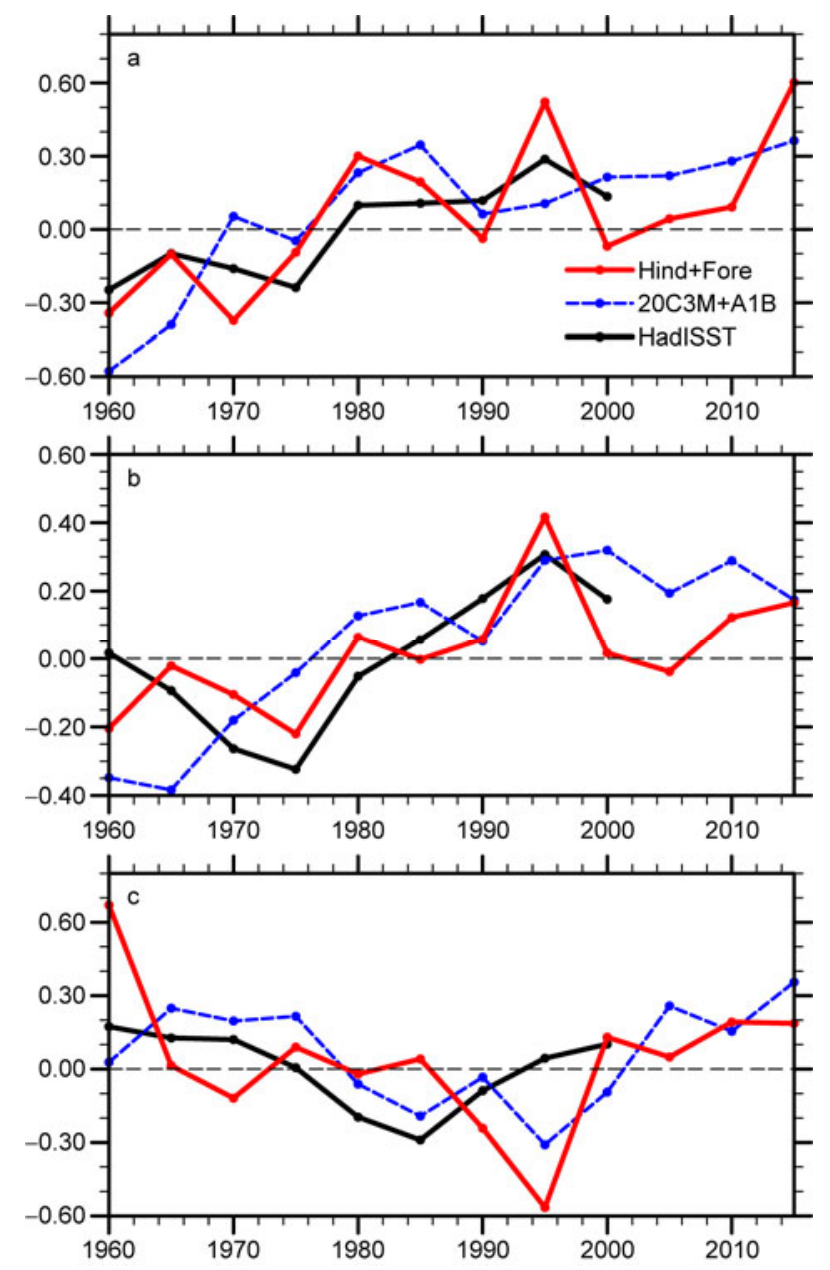

Figure 3 a, The temporal evolution of the area-averaged SST (units: K) in the tropical central-eastern Pacific $\left(10^{\circ} \mathrm{S}-10^{\circ} \mathrm{N}, 90^{\circ} \mathrm{W}-150^{\circ} \mathrm{W}\right)$. The red and blue lines represents results simulated by the Hindcast+Forecast runs and by the $20 \mathrm{C} 3 \mathrm{M}+\mathrm{A} 1 \mathrm{~B}$ run. The black lines represent the observation. Each point represents 10-year centered mean, e.g. 1960 represents 10 -year average of 1955-1964. b, Same as in a, but for the mid-latitude northeastern Pacific $\left(20^{\circ}-60^{\circ} \mathrm{N}, 105^{\circ}-140^{\circ} \mathrm{W}\right)$. c, Same as in a, but for the KOE region $\left(30^{\circ}-45^{\circ} \mathrm{N}, 140^{\circ}-175^{\circ} \mathrm{W}\right)$. 
another critical issue attracting much attention [7]. Figure 4 shows the temporal evolution of the global mean surface temperature in the observations and that simulated by the 20C3M+A1B run and Hindcast+Forecast runs. Compared with the observations and 20C3M run, the Hindcast runs fall unrealistically during 1960-1970. The bias may be associated with the model initialization process, which was started from 1950 and had not initialized the model sufficiently at the early stage. However, the global mean surface temperature simulated by the Hindcast runs is closer to the observation after 1970, especially in 1970-1995 than the 20C3m run. The prediction by the Forecast runs is also different from the projection by the A1B run. From 2000-2010, the Forecast runs increase much slower than the A1B run, while after that, the former surpasses the latter. The result is similar with the study of Keenlyside et al. [7]. Since the Forecast runs are started from the initialized ocean state, it should have higher skills in capturing the nature decadal variability of the climate system than the A1B run. The decadal variability may offset or enhance the anthropogenic effects and thus temporary weaken or intensify the warming trend, and finally causes the differences between the prediction by the Hindcast runs and the projection by the A1B run.

\section{Discussion and conclusion}

The coupled global climate model FGOALS_gl developed in LASG/IAP was used to perform decadal hindcast and forecast integrations. The IAU scheme was applied to assimilate the ocean temperature and salinity over the upper $1000 \mathrm{~m}$ derived from the objective analysis data. The hindcast skill was evaluated by comparing with the 20C3M run. Based on the evaluation, we predicted the climate changes over the coming 20 years. The major conclusions are listed below.

(1) The IAU scheme shows higher skill in initializing the ocean variability, especially in the mid-latitude ocean interior.

(2) The Hindcast runs have high skill in simulating the

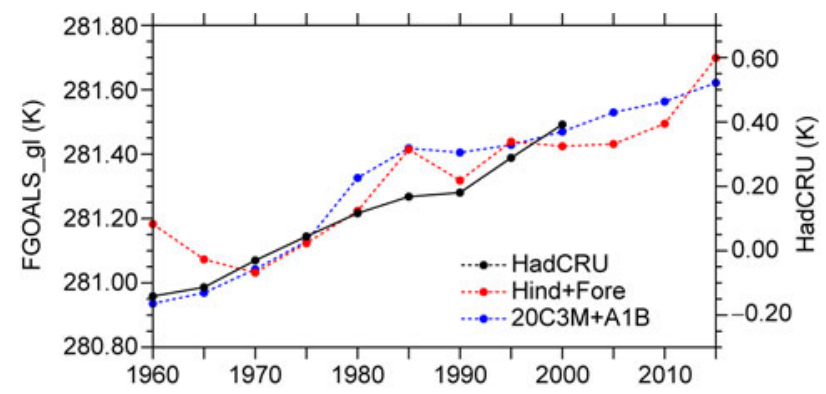

Figure 4 The temporal evolutions of the global mean surface temperature. Each point represents a 10-year centered mean. Black line represents observational global mean surface temperature anomalies (HadCRU data, right ordinate). Red and blue lines represent the global mean surface temperature simulated by the Hindcast+Forecast runs and 20C3M+A1B run, respectively (left ordinate). decadal variation of the SST in the tropical central-eastern Pacific and mid-latitude northeastern Pacific. It can realistically reproduce the phase changes of the SST anomalies in the two regions in the 1980s. In contrast, the skills of the 20C3M run in the two regions are much lower. The decadal climate variability is modulated by both external radiative forcing and internal variability of the climate system. Therefore, after considering the initial conditions through the model initialization and specifying the radiative forcing, we can use the CGCM FGOALS_gl to predict the decadal variability in some special regions.

(3) The Forecast runs indicate that at present, the SST in the tropical central-eastern Pacific has reached its trough phase, and will gradually increase over the next $10-15$ years. Meanwhile, the SST in the mid-latitude northeastern Pacific shows similar characteristics.

(4) The global mean surface temperature predicted by the Forecast runs increases significantly slower than that projected by the A1B run over 2000-2010. After that, the former warming rate accelerates and surpasses the latter. The prediction results are similar with the previous study by Keenlyside et al. [7], suggesting that the CGCM developed in LASG/IAP and the IAU initialization scheme is competent for the decadal prediction experiment in the CMIP5.

The skill of the decadal prediction by a CGCM is influenced by many factors, such as the predictability of decadal variability, the skill of the initialization schemes and the skill of the model in simulating decadal variability. The nature of the decadal variability and its predictability deserve further study. For example, some studies note that the decadal variability of the SST in the central-eastern Pacific is associated with the tropical air-sea interaction, but others argue that it results from tropical-mid-latitude interaction or remote forcing from the middle latitudes (more details seen in the review of Mestas-Nuñez and Miller [29]). The highest skill of the Hindcast runs of FGOALS_gl is seen in the tropical central-eastern Pacific, suggesting that the tropical air-sea interaction may be the main source of the predictability. In the future, we will conduct a so-called "Perfect model" idealized experiment [30] to further explore the predictability of the decadal variability of the tropical central-eastern Pacific.

Based on the above evaluation of the potential predictability, we will try to improve the initialization scheme. Because of the scarcity of data of the observational ocean circulation, we did not assimilate it in the study. However, we must note that the error of the circulation in the initial conditions may be one of the reasons that lower prediction skill, especially in the mid-latitude oceans where air-sea interaction is weak. We will explore whether the assimilation of the oceanic circulation has impacts on the decadal prediction through the "Perfect model" experiment.

It was stated in the introduction that the ECHAM5/MPIOM model shows higher skill in the prediction of the AMOC, while the Hindcast runs of the FGOALS_gl show 
little skill in predicting the AMOC (Figure 2a). The discrepancy of the FGOALS_gl may be associated with its lower skill in simulating the AMOC. The maximum of the AMOC in the Northern Hemisphere simulated by the FGOALS_gl is about $30 \mathrm{~Sv}$, much stronger than the 17-18 Sv in the best estimate based on observations. In contrast, the maximum of the AMOC in the ECHAM5/MPI-OM is about $20 \mathrm{~Sv}$, much closer to the best estimate than the FGOALS_gl.

This work was supported by the Strategic Priority Research Program of Chinese Academy of Sciences (XDA05110305), the National Basic Research Program of China (2010CB951904), the National Natural Science Foundation of China (41005040), the Program of Excellent State Key Laboratory (41023002), and the National High-Tech Research and Development Plan of China (2010AA012302).

1 Meehl G A, Goddard L, Murphy J, et al. Decadal prediction: Can it be skillful? Bull Amer Meteor Soc, 2009, 90: 1467-1485

2 Hurrell J, Meehl G A, Bader D, et al. A unified modeling approach to climate system prediction. Bull Amer Meteor Soc, 2009, 90: 18191832

3 Taylor K E, Stouffer R J, Meehl G A. An overview of CMIP5 and the experiment design. Bull. Am Meteorol Soc, 2012. 93, doi: 10.1175/ BAMS-D-11-00094.1

4 Lee T C K, Zwiers F W, Zhang X, et al. Evidence of decadal climate prediction skill resulting from changes in anthropogenic forcing. $\mathrm{J}$ Clim, 2006, 19: 5305-5318

5 Meehl G A, Washington W M, Collins W D, et al. How much more global warming and sea level rise? Science, 2005, 307: 1769-1772

6 Meehl G A, Stocker T F, Collins W D, et al. Global climate projections. Climate Change 2007: The Physical Science Basis. In: Solomon S, Qin D, Manning M, et al., eds. Contribution of Working Group I to the Fourth Assessment Report of the Intergovernmental Panel on Climate Change. Cambridge: Cambridge University Press, 2007. 747-845

7 Keenlyside N, Latif M, Jungclaus J, et al. Advancing decadal-scale climate prediction in the North Atlantic sector. Nature, 2008, 453: 84-88

8 Mochizuki T, Ishii M, Kimoto M, et al. Pacific decadal oscillation hindcasts relevant to near-term climate prediction. Proc Natl Acad Sci USA, 2010, 107: 1833-1837

9 Sugiura N, Awaji T, Masuda S, et al. Potential for decadal predictability in the North Pacific region. Geophys Res Lett, 2009, 36: L20701

10 Smith D, Cusack S, Colman A, et al. Improved surface temperature prediction for the coming decade from a global circulation model. Science, 2007, 317: 796-799

11 Zhou T J, Wu B, Wen X Y, et al. A fast version of LASG/IAP climate system model and its 1000-year control integration. Adv Atmos Sci, 2008, 25: 655-672

12 Wen X, Zhou T, Wang S, et al. Performance of a reconfigured atmospheric general circulation model at low resolution. Adv Atmos
Sci, 2007, 24: 712-728

13 Liu $\mathrm{H}$, Zhang $\mathrm{X}$, Li W, et al. An eddy-permitting oceanic general circulation model and its preliminary evaluations. Adv Atmos Sci, 2004, 21: 675-690

14 Bonan G B, Oleson K W, Vertenstein M, et al. The land surface climatology of the Community Land Model coupled to the NCAR Community Climate Model. J Clim, 2002, 15: 3123-3149

15 Briegleb B P, Bitz C M, Hunke E C, et al. Scientific description of the sea ice component in the Community Climate System Model: Version Three. NCAR Technical Note NCARTN-463+STR. 2004

16 Man W M, Zhou T J, Zhang J, et al. The 20th century climate simulated by LASG/IAP climate system model FGOALS_gl (in Chinese). Acta Meteorol Sin, 2011, 69: 644-654

17 Man W M, Zhou T J, Zhang L X. The tropical Pacific interannual variability simulated with LASG/IAP climate system model FGOALS_gl (in Chinese). Chin J Atmos Sci, 2010, 34: 1141-1154

18 Liu J W, Zhou T J, Wu C Q. Water Vapor and cloud radiative feedback processes in the ocean-atmosphere coupled model FGOALS_gl (in Chinese). Chin J Atmos Sci, 2011, 35: 531-546

19 Zhang J, Zhou T J, Man W M, et al. The transient simulation of Little Ice Age by LASG/IAP climate system model (in Chinese). Quat Sci, 2009, 29: 1125-1134

20 Zhou T J, Li B, Man W M, et al. A comparison of the Medieval Warm Period, the Little Ice Age and the 20th Century Warming simulated by FGOALS climate system model. Chin Sci Bull, 2011, 56: 3028-3041

21 Zhu Y M, Yang X Q, Yu Y Q, et al. Decadal variability in the North Pacific as simulated by FGOALS_g fast coupled climate model. Chin J Geophys, 2008, 51: 58-69

22 Bloom S C, Takacs L L, Silva A M D, et al. Data assimilation using Incremental Analysis Updates. Mon Weather Rev, 1996, 124: 12561271

23 Guinehut S, Coatanoan C, Dhomps A L, et al. On the use of satellite altimeter data in Argo quality control. J Atmos Oce Tech, 2009, 26 : 395-402

24 Brohan P, Kennedy J J, Harris I, et al. Uncertainty estimates in regional and global observed temperature changes: A new dataset from 1850. J Geophys Res, 2006, 111: D12106

25 Rayner N A, Parker D E, Horton E B, et al. Global analyses of sea surface temperature, sea ice, and night marine air temperature since the late nineteenth century. J Geophys Res, 2003, 108: 4407

26 Schott F A, Xie S P, McCreary Jr J P. Indian Ocean circulation and climate variability. Rev Geophys, 2009, 47: RG1002

27 Zhu Y, Yang X. Joint propagating patterns of SST and SLP anomalies in the North Pacific on bidecadal and pentadecadal timescales. Adv Atmos Sci, 2003, 20: 694-710

28 Qiu B. Kuroshio Extension variability and forcing of the Pacific decadal oscillations: Responses and potential feedback. J Phys Ocean, 2003, 33: 2465-2482

29 Mestas-Nuñez A M, Miller A J. Interdecadal variability and climate change in the eastern tropical Pacific: A review. Prog Ocean, 2006, 69: 267-284

30 Meehl G A, Hu A, Tebaldi C. Decadal prediction in the Pacific Region. J Clim, 2010, 23: 2959-2973

Open Access This article is distributed under the terms of the Creative Commons Attribution License which permits any use, distribution, and reproduction in any medium, provided the original author(s) and source are credited. 